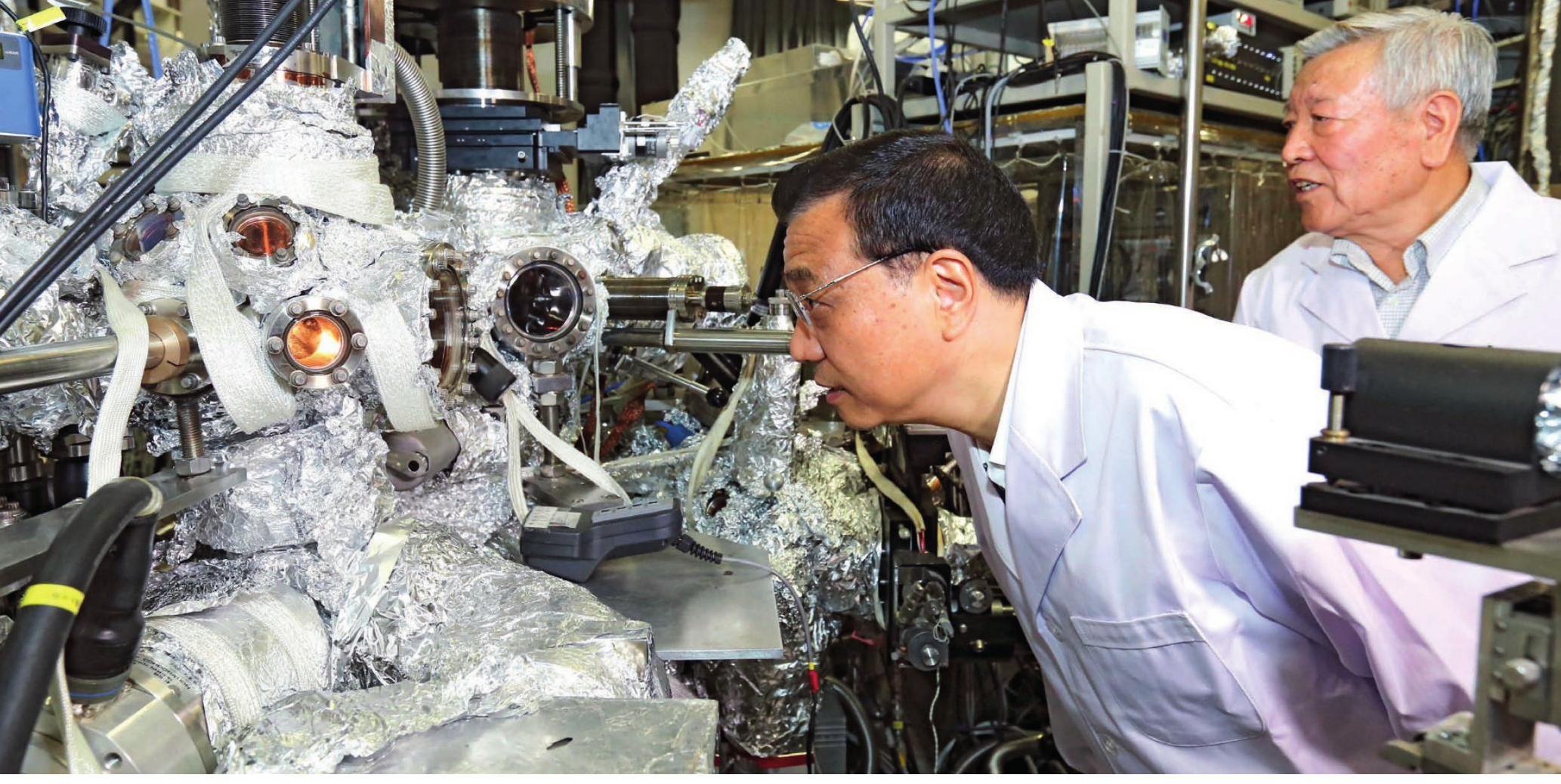

Chinese Premier Li Keqiang (L) visits the National Lab for Superconductivity at the Institute of Physics of the Chinese Academy of Sciences in Beijing.

\title{
Building an innovator
}

\author{
When it comes to translating its own research into practical applications, China falls short. \\ A forum in Shanghai put the spotlight on ambitious plans to accelerate the process.
}

\section{BY NICKY PHILLIPS}

$\mathrm{F}$ Trom a portable ultrasound machine that improves diagnosis in rural hospitals to unmanned military drones, China has excelled at adapting ideas and technologies for its large domestic market. "From an industrial research perspective, what's really important is to translate cutting-edge science into real applications," says Xiangli Chen, general manager of General Electric China Technology Center in Shanghai. "And that we're very good at."

Chen was speaking at the 2015 International Forum: From Research to Innovation and Entrepreneurship in Shanghai, which was cosponsored by the Shanghai Association for Science and Technology (SAST), the Chinese Academy of Sciences Shanghai branch, the Shanghai newspaper the Wenhui Daily and Springer Nature (publisher of Nature). Scientists, policymakers and leaders of academia and industry gathered at the meeting to discuss how China can build a sustainable innovation ecosystem. Although the nation has mastered the art of tinkering and scaling up other countries' research and ideas, the forum discussed the elements China needs to transform its own scientific research into products, services and technologies.

China sees its future economic growth and social prosperity as being directly tied to how well it can innovate - and in particular, how well it can create truly new products driven by scientific research. The government's 2016 five-year plan lists this as its top priority.

Many countries have similar goals, but the scale of the Chinese government's investment and influence sets the country apart. In the past 15 years, China has more than doubled the percentage of its gross domestic product that it spends on research and development (R\&D). National, provincial and local governments offer generous funding for almost anything related to innovation and entrepreneurship, and education reforms mean that schools are encouraged to foster the next generation of innovators. May Lee, the dean of the School of Entrepreneurship and Management at ShanghaiTech University, and a moderator at the forum, said that the country was well versed in scaling up programmes to capitalize on its large population. "Even if only $0.1 \%$ of the population are coming up with breakthroughs," Lee told Nature, "China can generate more than anyone else because the population is so big."

Despite China's ambition and investment, a 2015 report by the McKinsey Global Institute (E. Roth et al. The China Effect on Global Innovation; McKinsey \& Company, 2015) found that the country's efforts were "yet to give China a lead in science-based innovation". The authors acknowledged that this kind of innovation often has a long lead time - it can, for instance, take years of investment to produce and commercialize new drugs or crop varieties. But they also found that under-investment in basic science, limited incentives for private $\mathrm{R} \& \mathrm{D}$ and regulatory bottlenecks that restricted market access to innovative products were all holding back the country's progress. Although some observers say that it is too early to assess whether China's top-down approach will provide a return on its substantial investment, others predict that only when the central government steps aside and allows market forces to prevail will sciencebased innovation truly flourish.

\section{HUMAN CAPITAL}

"It's people who innovate," said Bernard Meyerson, IBM's chief innovation officer, during his keynote speech. "But it's a special type of person." Innovators must be experts in their field, but also able to communicate their ideas to their colleagues, grant providers, investors and consumers, he said.

China trains about 30,000 science and engineering $\mathrm{PhD}$ students each year, but they were educated in a system that valued published papers over the entrepreneurial skills that are valuable to industry. Companies 
still complain of skill gaps among science, technology, engineering and maths graduates, according to the McKinsey report. But Lee says that's changing. A raft of education reforms to train students to be creative thinkers is being rolled out at the school and university levels. Changes to school curricula include increasing opportunities for students to be creative, curious and to learn by doing, she says.

It will take a decade or more for these initiatives to have a significant effect, and so the central government is encouraging thousands of Chinese scientists who are living abroad to return home to launch their own companies or labs. For now, the government is relying on these Chinese-born, Western-trained scientists and entrepreneurs to run labs and train $\mathrm{PhD}$ students and junior scientists. The ' 1000 Talents Plan' has far exceeded its eponymous goal. Since 2009, it has enticed more than 4,000 high-level scientists back to China with incentives such as high salaries. This has also meant paying to relocate many of the scientists' families, often from the United States, Europe, Japan and Singapore. Thomas Kenny, a mechanical engineer at Stanford University in California, says that returning scientists provide an "infusion of talent" that can have an immediate effect on the country's growing innovation ecosystem.

Several speakers at the forum, including Kenny, warned that China should avoid treating all innovators the same. Many universities in the United States expect scientists to be both great teachers and savvy entrepreneurs, but "often the skills and duties of an entrepreneur and teacher are conflicting", says Kenny, who has had both roles in his career. "Entrepreneurs and CEOs have to be ruthless; professors have to be mentors," he says. "It's dangerous to think those roles overlap much."

Cong Cao, a science-policy specialist at the University of Nottingham's campus in Ningbo, China, says that local faculty members face similar pressures. He is also concerned that the generous funding allowances offered to some academics may lead to conflicts of interest if they also try to set up their own start-up companies. "Maybe a professor uses his or her students or lab facilities for their business instead of using it for research at the university," Cao told Nature. He suggests that China should follow the Stanford model, which allows academics to take a break from academia when pursuing business opportunities, but return to their faculty positions later.

\section{BEHIND THE PACK}

During a panel discussion on the part institutions can play in encouraging innovation, Jian Lu, vice-president of research at the City University of Hong Kong, said that good science would always find an application eventually, regardless of whether it was funded with specific applications in mind. But China has a paucity of basic research. An independent analysis by Nature Publishing Group called

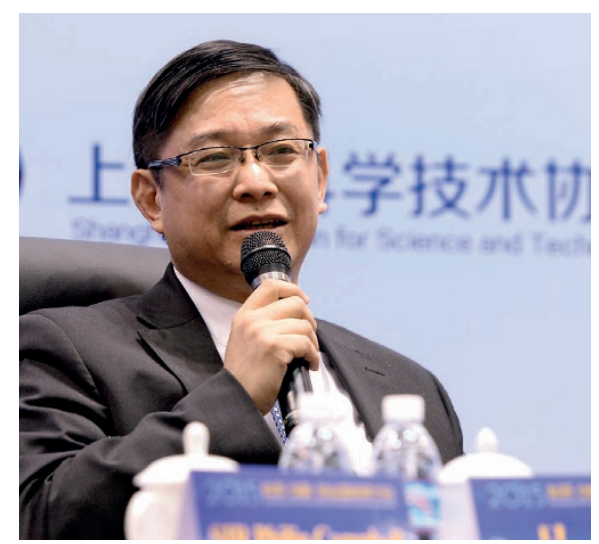

Jian Lu of the City University of Hong Kong.

Turning Point: Chinese Science in Transition (see go.nature.com/ybsatt) found that China spends only $5 \%$ of its R\&D expenditure on basic science, compared with $18 \%$ by the United States and $16 \%$ by the United Kingdom. In the report, four out of five high-level scientists interviewed agreed that China needed to invest more in basic research. "You've got to do basic science to have ideas that will eventually drive innovation in 10-20 years," said Chen, during a panel discussion at the Shanghai event.

Most Chinese R\&D money goes to areas of research with more immediate commercial promise, and this has spurred a marked increase in patent applications over the past 15 years. Inventors in China applied for more than 1 million patents in 2015 - the fifth year in a row that the country has filed the highest number. Government subsidies, however, have contributed to the rise in applications, some of which represent low-quality patents that do not translate into commercial successes (J. Dang \& K. Motohashi China Economic Rev. 35, 137155; 2015).

China's university technology-transfer offices still have a lot to learn about advising scientists and entrepreneurs on how to identify whether a patentable discovery has commercial value, says Ching Zhu, managing partner at venturecapital firm Frontline BioVentures in Shanghai. Although in 2013 China published $17 \%$ of the world's life-sciences papers, and in 2012 held 1 in 10 global life-sciences patents, the country launched only $2 \%$ of the world's new drugs that year. Chinese companies spend less on R\&D as a percentage of their sales than their global competitors. One company that is generating knowledge is biotechnology giant BGI in Shenzhen, which employs more than $2,000 \mathrm{PhD}$ graduates. It recently partnered with the Chinese Academy of Agricultural Sciences and the International Rice Research Institute to sequence 3,000 rice varieties, which will allow the fast-track development of disease-resistant plants.

\section{QUASHING IP THEFT}

In the past, failure to effectively enforce intellectual property (IP) laws in China has deterred early-stage investors and venture capitalists from commercializing research discoveries. China is now trying to address this problem. "There is now a recognition and a serious effort on behalf of the government and industry to stamp out rampant IP theft," says Meyerson. Such policies will also help China's small, but growing, private venturecapital market to expand, says Zhu. China has plenty of capital, but lacks entrepreneurs who know how to connect scientists with potential investors - an essential component of a vibrant venture-capital industry - and this is keeping the market small. Investors would also like to see a more stable capital market. "In China, sometimes the market can be closed for months at a time," says Zhu. "There is a lot of government control." Zhu is confident that recent reforms such as reopening of the stock market to new listings and the Shanghai Stock Exchange's plan to introduce a market for small, innovative companies will increase investor confidence.

Despite China's efforts to adopt the policies that have led to the development of successful innovation cultures, such as those that helped to establish Silicon Valley, Cong says that in some instances, the Chinese government's involvement reduced the impetus for corporations to foster their own innovation pipelines driven by market needs. For instance, the central government's push to promote research commercialization has led to the construction of more than 100 high-tech science parks since the 1980s. But many of these hubs for science and industry collaboration have "homogenous development strategies", which have contributed to the oversupply of Chinesemade products such as solar- and wind-power technologies, says Cao. "Some things you can do top-down, but innovation you really need to have grow from the bottom, up." To promote innovation, he said, the role of government should be to create the right environment, with strong IP laws and funding for basic research.

But George Yip, a research specialist at China Europe International Business School in Shanghai, says that there are some obvious benefits to the central government's involvement: specifically, the size of the 88-million- member Communist Party. Through such a vast organization, the government can vigorously pursue its innovation goals at every level of Chinese society. "It's not just that China is top-down, it's that it reaches everywhere," said Yip.

Given China's current economic development, Lee also feels that the central government's approach is the right one. But she is not sure how long for, or how much it should shift to a system driven by entrepreneurs and the needs of the market. "Some amount of that must happen. But it could be very China specific and utterly different from what we've seen elsewhere."

Nicky Phillips is a senior editor with Nature Publishing Group in Sydney, Australia. 